\title{
Ionized Calcium Measurement
}

National Cancer Institute

\section{Source}

National Cancer Institute. Ionized Calcium Measurement. NCI Thesaurus. Code C81948.

The determination of the amount of ionized calcium present in a sample. 